\title{
Numerical estimation of the thermal stability boundaries for the process of thermochemical conversion processes of biomass in quasi-equilibrium approximation
}

\author{
Igor Donskoy ${ }^{1, *}$ \\ ${ }^{1}$ Melentiev Energy Systems Institute, SB RAS, 130 Lermontova st,, Irkutsk, Russia
}

\begin{abstract}
The stationary process of pyrolysis and gasification of plant biomass in a wide range of conditions is considered. The reaction rate in a multicomponent system is a complex function of composition and temperature. To simplify the calculations, we use the approximation of the brutto-reaction: it is supposed that a slow reaction of thermal decomposition of biomass proceeds in the reaction zone with first order kinetics and Arrhenius dependence on temperature. Gas phase reactions rates are considered to be high enough to apply the quasi-equilibrium approximation. Calculations make it possible to estimate the temperature values at the boundary of thermal stability and the position of this boundary for different residence times of biofuel in the reaction zone.
\end{abstract}

\section{Introduction}

The analysis of stationary states of chemical reactors is one of the important problems in chemical technology. The multiplicity of stationary states and their stability affect the choice of conditions for carrying out chemical processes, including for energy use [1]. As is known from the theory of chemical reactors stability, the interaction of a chemical reaction and heat transfer can lead to complex dynamic behaviour [2]. Stable stationary modes are possible with a suitable ratio of the rate of chemical reaction and transfer processes. The boundary of the existence of such modes is determined by the existence of a joint solution of equations describing chemical kinetics and heat and mass transfer [3].

Biomass is one of the promising fuels for renewable energy. A variety of processes have been proposed for thermochemical conversion of biomass in reactors of different types: fixed-bed, fluidized-bed, entrained flow, combined [4, 5]. The biomass decomposition kinetics and the products composition are largely determined by the heat transfer, and therefore, on the particle size, hydrodynamic conditions, temperature level, etc. In paper [6], on the basis of a simple model, the conditions for the existence of stationary modes of fixed-bed combustion of biomass were obtained. In papers [7, 8], the process of biomass pyrolysis was investigated in the approximation of an isothermal perfectly stirred reactor using a kinetic mechanism based on work [9]. In present paper, a model is proposed that allows considering the pyrolysis and gasification processes of biomass using a simplified kinetic scheme, but for generalized heat transfer conditions. Chemical reactions description is reduced to equilibrium problem, and heat balance equation solutions are obtained in a wide range of heat transfer coefficient values.

\section{Mathematical model description}

The analysis is based on the well-known model of a perfectly stirred reactor: the composition of the input mixture is specified; the control parameters are the residence time of the reacting mixture in the reaction zone, as well as the heating temperature and the rate of heat transfer. In real reactors, the heat transfer characteristics and the heating temperature can vary in different regions of the reaction zone; however, for the sake of simplicity, the constancy (or averaging) of these values is assumed.

The heat and mass balance equations are written as follows:

$$
\begin{gathered}
\sum_{j} h_{j}\left(T^{0}\right) n_{j}^{0}=\sum_{j} h_{j}(T) n_{j}-\tau \alpha\left(T^{w}-T\right), \\
n_{j}^{0}-n_{j}=\tau r_{j}(\mathbf{n}, T) .
\end{gathered}
$$

Here $T$ is temperature, $\mathrm{K} ; n_{j}$ is amount of $j$-th component, mol; $r_{j}$ is reaction rate in relation to $j$-th component, $\mathrm{mol} / \mathrm{s} ; h$ is specific enthalpy, $\mathrm{J} / \mathrm{mol}$; $\tau$ is residence time, $\mathrm{s} ; \alpha$ is generalized heat transfer coefficient, $\mathrm{W} / \mathrm{K}$. Superscript 0 is refers to input flow; superscript $w$ refers to averaged temperature of environment (or reactor wall).

The reaction rate in a multicomponent system is a complex function of composition and temperature. To simplify the calculations, we use the approximation of the brutto-reaction: we believe that the first order reaction of biomass thermal decomposition proceeds in

* Corresponding author: donskoy.chem@ mail.ru 
the reaction zone under kinetic control, and its dependence on temperature can be approximated by Arrhenius equation [10]. We consider the rates of gasphase reactions to be high enough to apply the quasiequilibrium approximation for them [11, 12]. In this case, the degree of biomass conversion can be used as a reaction coordinate $\xi$ :

$$
\xi=\frac{\tau K}{1+\tau K}
$$

Here $K$ is pyrolysis brutto-reaction rate coefficient:

$$
K=K_{0} \exp \left(-\frac{E_{a}}{R_{g} T}\right)
$$

Then, for each value of $\xi$, it is possible to determine the elemental composition of volatile substances, which is then distributed over molecular forms in accordance with the conditions of chemical equilibrium [13, 14]. Biomass conversion products composition is found as a solution of the following problem:

$$
\begin{gathered}
\mathbf{n}^{e q}=\arg \min G(\mathbf{n}) \\
\operatorname{An}=\mathbf{b}(\xi) \\
n_{j} \geq 0 \forall j \\
G(\mathbf{n})=\sum_{j} \mu_{j}(\mathbf{n}, T) n_{j}
\end{gathered}
$$

Here $\mathbf{A}$ is elemental composition matrix; $\mathbf{b}$ is elemental composition vector; $G$ is Gibbs free energy of considered system; $\mu_{j}$ is chemical potential of $j$-th component. Then the heat balance equation in the reactor can be rewritten as follows:

$$
\sum_{j} h_{j}\left(T^{0}\right) n_{j}^{0}=\sum_{j} h_{j}(T) n_{j}^{e q}-\tau \alpha\left(T^{w}-T\right)
$$

In the general case, the relationship between $\mathbf{n}^{e q}$ and $\mathbf{n}^{0}$ is not expressed by explicit analytical dependences, so the problem is solved numerically. The direct problem of determining the temperature is often difficult due to the large number of terms that depend on it. Therefore, the inverse problem is usually solved: for a given temperature, other variables are varied to ensure the solution of the heat balance equation. When using the equilibrium model to determine the composition of pyrolysis products, the residence time is also considered as fixed parameter. Then the closure coefficient is $\alpha$, determined for fixed values of the reaction temperature and residence time:

$$
\alpha=\frac{\sum_{j} h_{j}\left(T^{0}\right) n_{j}^{0}-\sum_{j} h_{j}(T) n_{j}^{e q}}{\tau\left(T-T^{w}\right)}
$$

The calculations used the thermodynamic properties of substances from the reference book [15]. The enthalpy of the fuel was estimated taking into account the heat of combustion, which was determined by the empirical formula [16]. The equilibrium composition was numerically determined using the Shirkalin's algorithm [17] for an ideal system. The following coefficients are accepted for calculations: $K_{0}=10^{7} \mathrm{~s}^{-1} ; E_{a}=110 \mathrm{~kJ} / \mathrm{mol}$ [18]. We assume that pyrolysis takes place in a nitrogen atmosphere (1 $\mathrm{kg} / \mathrm{kg}$ of fuel). The residence time $\tau$ determines the type of reactor used: for fixed-bed reactors, $\tau$ can be on the order of $10^{3}-10^{4} \mathrm{~s}$; for fluidized bed reactors or cyclone reactors $\tau$ is on the order of 1-10 seconds. The heating temperature ranges from $500 \mathrm{~K}$ (torrefaction) to $1000 \mathrm{~K}$ (high-temperature pyrolysis). The generalized heat transfer coefficient $\alpha$ has the dimension $\mathrm{W} / \mathrm{K}$, i.e. it includes, generally speaking, the area of heat exchange between particles and the heating medium. This area, in turn, depends on the specific surface of the particles, i.e. is inversely proportional to their average size. Therefore, higher values of $\alpha$ correspond to either intense heat transfer (due to thermohydrodynamic factors) or fine fuel particles. Thermal resistance of particles (internal processes such as thermal conductivity and filtration of products and their influence on the kinetics of pyrolysis) is not taken into account (constraints for validity of this approximation may be estimated using more detailed models [19]). The initial moisture content of the biomass varies from 10 to $40 \%$ wt., all calculations are made for $1 \mathrm{~kg}$ of wet biomass. Elemental composition of dry biomass is as follows: $\mathrm{C}^{d a f}=49.19 \% ; \mathrm{H}^{d a f}=6.36 \%$; $\mathrm{O}^{d a f}$ $=42.06 \% ; \mathrm{N}^{d a f}=2.06 \% ; \mathrm{S}^{d a f}=0.01 \%$.

\section{Biomass pyrolysis}

The dependence of the fuel conversion degree on temperature is shown in Fig. 1. This diagram gives an idea of the timescale of biofuel conversion processes: torrefaction requires long residence times; with an increase in temperature, the process is significantly intensified. The reaction rate and composition of pyrolysis products in chosen approximation depend only on temperature; therefore, the thermochemical efficiency of the pyrolysis process is also determined only by the temperature and residence time. The calorific value of the gas, in addition to the temperature and residence time, depends on the moisture content of the fuel: the higher the initial moisture content, the lower the calorific value (Fig. 2).

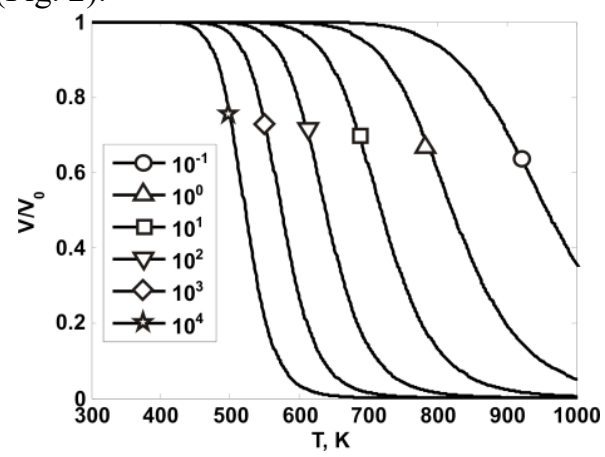

Fig. 1. Dependence of residue volatile content on temperature and residence time.

Of greater interest is the dependence of the reactor temperature on the heat transfer coefficient. At a heating temperature of $500 \mathrm{~K}$, when the maximum fuel conversion is only $25 \%$, the reactor temperature monotonically depends on the heat transfer coefficient. At $373 \mathrm{~K}$, step is observed associated with the water 
phase transition. At higher heating temperature and long residence times, there are two stable stationary states for low values of the heat transfer coefficient: the equilibrium thermal effect turns out to be positive, therefore, self-heating occurs to a temperature of about $700 \mathrm{~K}$ (Fig. 3, 4). With an increase in moisture content, the total thermal effect decreases due to the heat consumption for evaporation, so dependence becomes monotonous again. If, at a moisture content of $10 \%$, the curves for $\tau=10^{3} \mathrm{~s}$ and $\tau=10^{4} \mathrm{~s}$ undergo a discontinuity in a range of $500-700 \mathrm{~K}$ (the value of $\alpha$ becomes undefined), then at a moisture content of $20 \%$ and $\tau=$ $10^{4} \mathrm{~s}$, the curve returns to the limit value without selfheating. The beginning of the section with the effect of self-heating falls on the range from $500 \mathrm{~K}$ and higher, therefore, in the previous case, only one stationary state was observed for all values of the parameters. The same temperature dependence on the heat transfer coefficient is observed at high heating temperatures.
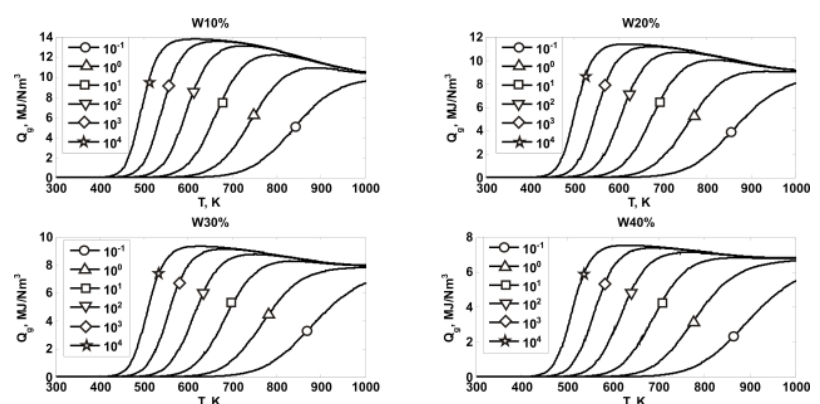

Fig. 2. Dependence of pyrogas heating value on temperature and residence time.
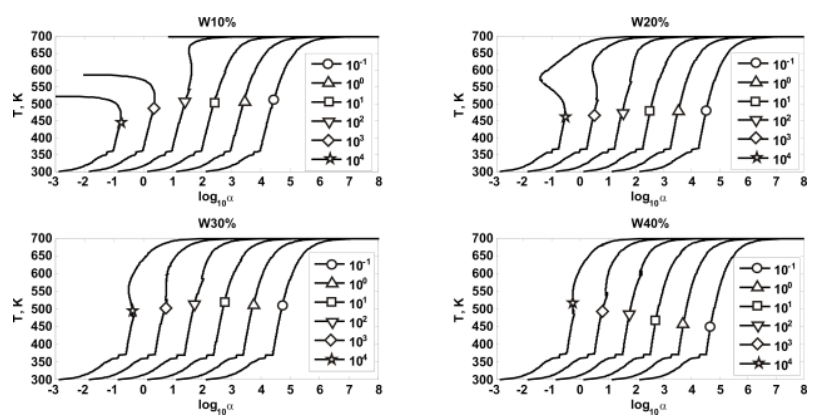

Fig. 3. Dependence of stationary pyrolysis temperature on heat transfer coefficient and residence time (wall temperature $700 \mathrm{~K}$ ).
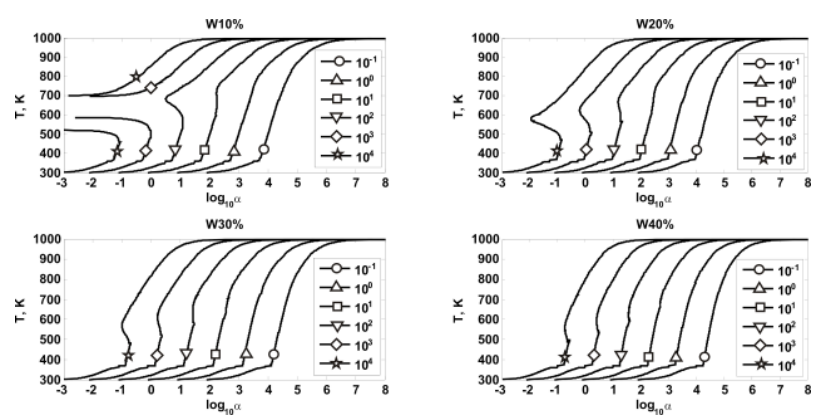

Fig. 4. Dependence of stationary pyrolysis temperature on heat transfer coefficient and residence time (wall temperature $1000 \mathrm{~K}$ ).

Analysis of thermodynamic properties of biomass and pyrolysis products shows that equilibrium thermal effect turns out to be exothermic at low moisture content and temperatures of 300-700 K. Taking into account the reaction rate, this range narrows to 500-700 $\mathrm{K}$. At a humidity of $20 \%$, the thermal effect no longer falls into the exothermic region, however, due to the nonmonotonic dependence of the thermal effect on temperature, bends are observed (i.e. at different values of the heat transfer coefficient, the amount of transferred heat changes disproportionately).

\section{Biomass gasification}

Calculations of biomass gasification process characteristics were carried out for a moisture content of $10 \%$ wt. In the gasification process, air is used as gasification agent (the mass flow ratio of air/biomass varies from 1 to 6 ). In the calculations, the yield of solid carbon is not fixed, it is determined by the equilibrium conditions of heterogeneous reactions. It is still assumed that the rate of the process is determined by the pyrolysis stage (more precisely, pyrolysis is the initiating stage). The temperature of the gasification process is determined in the same way as for the pyrolysis process. Air gasification is in all cases an autothermal process; therefore, the temperature $T^{w}$ is $300 \mathrm{~K}$, i.e. only heat loss is considered. The calculation results are presented below.
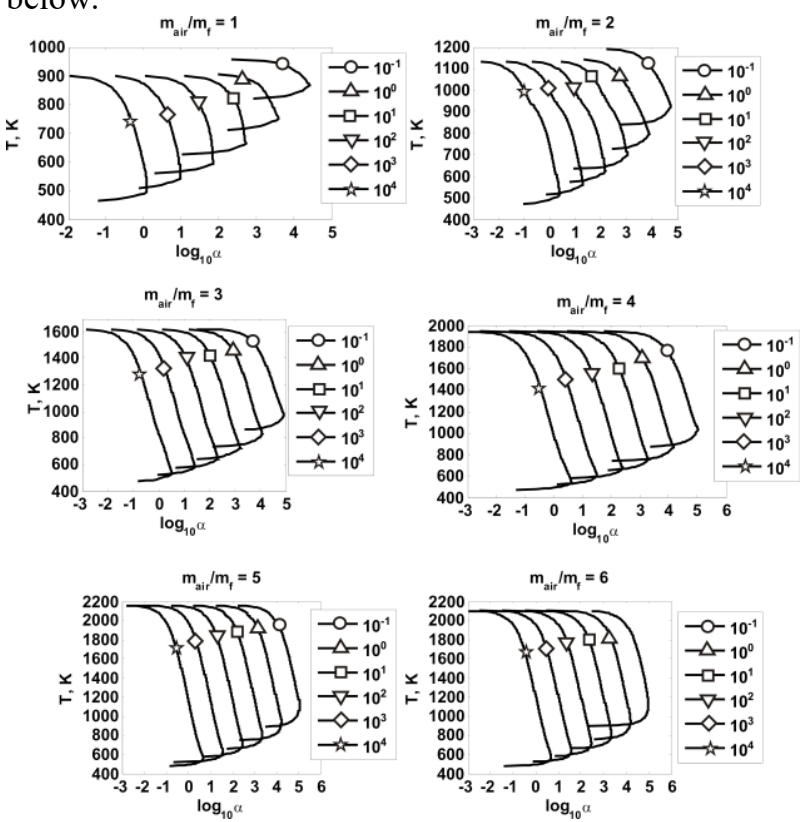

Fig. 5. Dependence of gasification temperature on heat transfer coefficient, residence time and air/biomass ratio.

There is a critical value of heat transfer coefficient, above which a steady-state gasification process becomes impossible. This value corresponds to the limit point of the stationary process temperature dependence on $\alpha$ (Fig. 5). Naturally, with decreasing $\tau$, the maximum value of $\alpha$ shifts to the region of large values. The cold gas efficiency of gasification process is determined, first of all, by the air-fuel ratio: at $m_{\text {air }} / m_{f}=2$, the gasification process shows efficiency that is close to optimal (Fig. 6). At a lower specific air flow rate, the cold gas efficiency turns out to be low due to the low degree of fuel 
conversion; at high specific flow rates, oxidation of combustible gas components occurs (see Fig. 7).

The critical value of the coefficient $\alpha$, as indicated above, depends on the residence time $\tau$, and for all the considered values of the specific consumption, this dependence behaves like a power function with an exponent of about -0.87 (Fig. 8). The critical value of the coefficient $\alpha$ increases with an increase in the specific air consumption. Since the maximum temperature of the process changes not so much with the value of $\tau$, the biomass gasification process decays at an approximately constant level of heat loss.
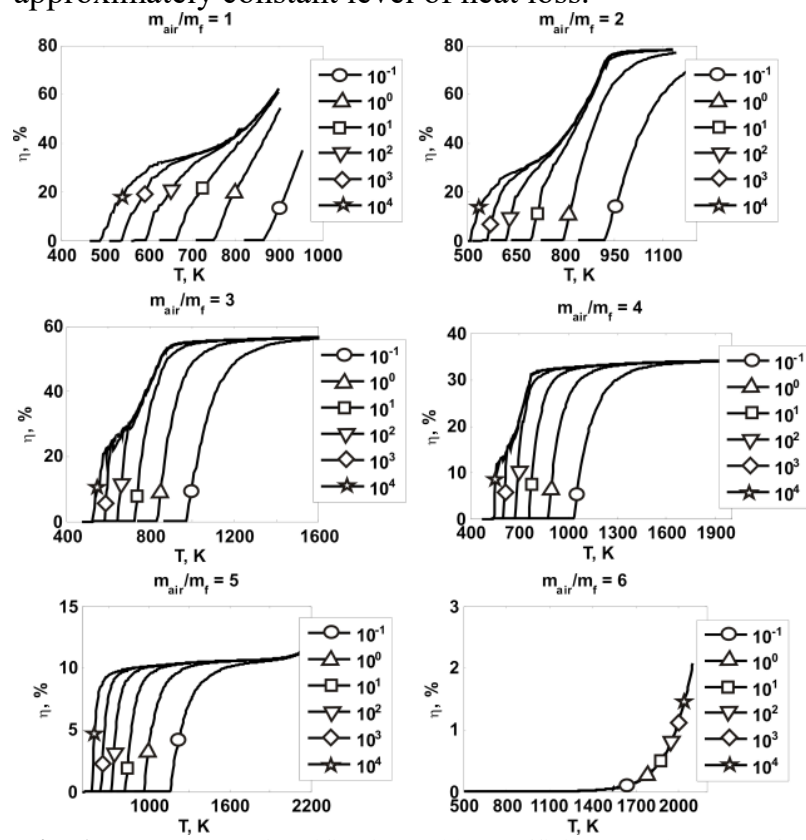

Fig. 6. Dependence of gasification cold gas efficiency on heat transfer $\underset{\mathrm{m}, / \mathrm{m}_{\mathrm{t}}=1}{\text { coeficient, }}$, residence time and air/biomass ratio.
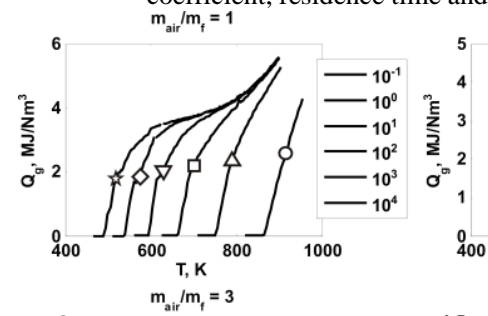

$\mathrm{m}_{\text {air }} / \mathrm{m}_{\mathrm{f}}=2$
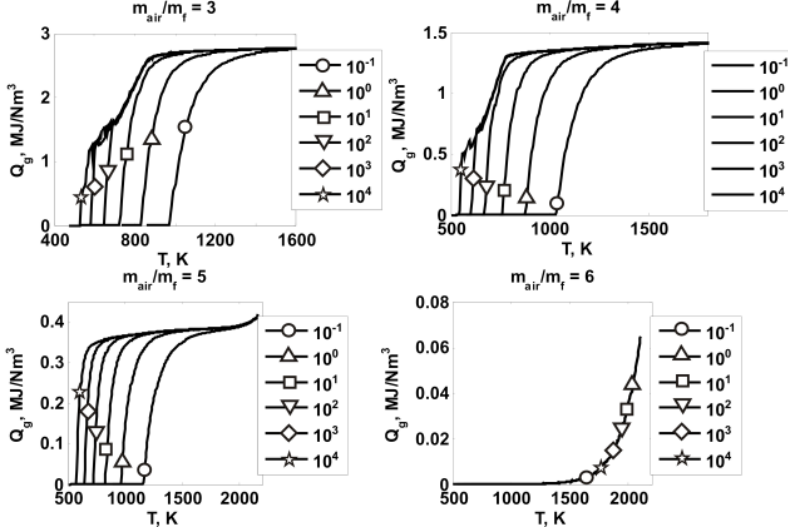

Fig. 7. Dependence of produced gas heating value on heat transfer coefficient, residence time and air/biomass ratio.
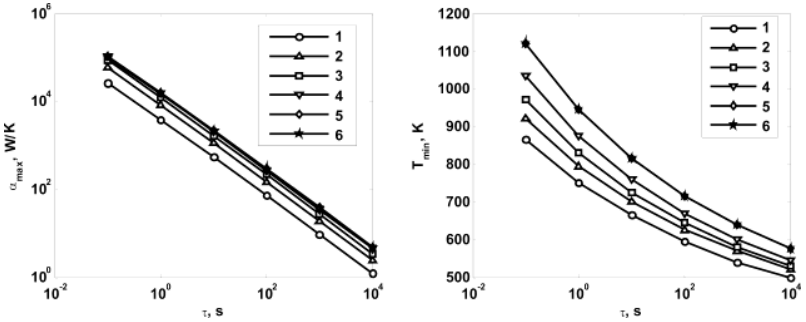

Fig. 8. Dependence of critical heat transfer coefficient and minimum temperature on residence time and air/biomass ratio.

\section{Conclusions}

In this work, using classical methods of thermal stability analysis of chemical reactors, the processes of pyrolysis and air gasification of plant biomass are studied in a wide range of heat transfer conditions and residence times (long residence time for fixed-bed reactors, short residence time for flow reactors). To describe the chemical composition of the reaction system, a kineticthermodynamic model is used: the limiting heterogeneous processes are taken into account explicitly, and the composition of the gas phase is considered to be in equilibrium. The calculation results give relationships between the characteristics of biomass conversion (fuel conversion, gas composition) and heat transfer conditions. At temperatures of about $700 \mathrm{~K}$, the thermal decomposition of biomass becomes exothermic process; therefore, pyrolysis can proceed in an autothermal mode. With increasing moisture content, the self-heating effect gradually disappears. Under gasification conditions, in all cases, there is a single high-temperature stationary solution, limited by the limiting value of the effective heat transfer coefficient. Calculations make it possible to estimate the temperature values at the boundary of thermal stability and its dependence on the residence time.

This work is financially supported by an international collaborative project (BRICS2019-040) under the BRICS STI Framework Programme with government funding organizations of Brazil CNPq (402849/2019-1), Russia RFBR (19-58-80016), India DST (CRG/2018/004610, DST/TDT/ TDP-011/2017), China MOST (2018YFE0183600), and South Africa NRF (BRIC190321424123). Equipment of multi-access center "High-Temperature Circuit" (MESI SB RAS) was used in this study.

\section{References}

1. E. Ranzi, M. Corbetta, F. Manenti, S. Pierucci, Chem. Eng. Sci. 110, 2 (2014). DOI: 10.1016/j.ces.2013.08.014

2. V. Hlavacek, M. Kubicek, J. Jelinek, Chem. Eng. Sci. 25, 1441 (1970). DOI: 10.1016/00092509(70)85067-9

3. V. Balakotaiah, D. Luss, Chem. Eng. Sci. 37, 1611 (1982). DOI: 10.1016/0009-2509(82)80030-4 
4. W.M. Lewandowski, M. Ryms, W. Kosakowski, Processes 8, 516 (2020). DOI: 10.3390/pr8050516

5. Coal and biomass gasification. Recent advances and future challenges, Springer, 2018. 524 p. DOI: 10.1007/978-981-10-7335-9

6. I.G. Donskoy, Vestnik tekhnologicheskogo universiteta, 23(12), 135, 2020. [in Russian]

7. A. Mlonka-Medrala, P. Evangelopoulos, M. Seiradzka, M. Zajemska, A. Magdziarz, Fuel 296, 120611 (2021). DOI: 10.1016/j.fuel.2021.120611

8. M. Sieradzka, P. Rajca, M. Zajemska, A. MlonkaMedrala, A. Magdziarz, J. Cleaner Prod. 248, 119277 (2020). DOI: 10.1016/j.jclepro.2019.119277

9. E. Ranzi, T. Faravelli, F. Manenti, Adv. Chem. Eng. 49, 1 (2016). DOI: 10.1016/bs.ache.2016.09.001

10. A. Anca-Couce, Progr. Energy Combust. Sci. 53, 41 (2016). doi:10.1016/j.pecs.2015.10.002

11. P. Kangas, P. Koukkari, M. Hupa, Energy Fuels, 28 6361 (2014). DOI: 10.1021/ef501343d

12. I.G. Donskoi, Russ. J. Appl. Chem. 93, 519 (2020). https://doi.org/10.1134/S1070427220040060

13. I.G. Donskoi, A.V. Keiko, A.N. Kozlov, D.A. Svishchev, V.A. Shamanskii, Therm. Eng. 60, 904 (2013). DOI: 10.1134/S0040601513120069

14. I.G. Donskoi, A.N. Kozlov, D.A. Svishchev, V.A. Shamanskii, Therm. Eng. 64, 258 (2017). DOI: 10.1134/S0040601517040024

15. V.P. Glushko, L.V. Gurvich, Thermodynamic properties of individual substances: Volume 1. (1988).

16. A.A. Agroskin, V.B. Gleibman, Solid fuel thermophysics, Moscow, Nedra (1980). [in Russian]

17. A.N. Gorban, B.M. Kaganovich, S.P. Filippov, A.V. Keiko, V.A. Shamansky, I.A. Shirkalin, Thermodynamic equilibria and extrema. Analysis of attainability regions and partial equilibria, BerlinHeidelberg-New York, Springer (2006).

18. L. Sorum, M.G. Gronli, J.E. Hustad, Fuel 80, 1217 (2001). DOI: 10.1016/S0016-2361(00)00218-0

19. I. Haberle, O. Skreiberg, J. Lazar, N.E.L. Haugen, Progr. Energy Combust. Sci. 63, 204 (2017). DOI: 10.1016/j.pecs.2017.07.004 